\title{
The psychotic end of the spectrum Andreas Marneros
}

Address: Psychiatric Clinic, Martin Luther University Halle-Wittenberg, Halle, Germany

from International Society on Brain and Behaviour: 3rd International Congress on Brain and Behaviour

Thessaloniki, Greece. 28 November - 2 December 2007

Published: 17 April 2008

Annals of General Psychiatry 2008, 7(Suppl I):S79 doi:I0.1186/1744-859X-7-SI-S79

This abstract is available from: http://www.annals-general-psychiatry.com/content/7/SI/S79

(C) 2008 Marneros; licensee BioMed Central Ltd.

There is no empty room between the two prototypes "schizophrenia" and "mood disorders". Even the prototypes themselves are not monolithic, but constitute spectra of disorders, i. e. the bipolar, the depressive, and the schizophrenic spectrum. The boundaries between them are not an iron curtain but they are elastic and permeable. These spectra overlap on various levels: on the phenomenological, prognostic, sociodemographic, premorbid, genetic, biological, pharmacological and other levels. The overlap of the schizophrenic and mood spectra results in clinical conditions such as schizoaffective disorders, acute and transient psychotic disorders, mood disorders with mood-incongruent psychotic symptoms etc. Based on longitudinal clinical data on a) schizoaffective disorders, b) mood disorders with mood-incongruent symptoms, and c) acute and transient psychotic disorders, the overlap of the spectra or the psychotic continuum will be defined.

The polymorphic long-term course of bipolar disorders and the differences and similarities between mood-dominated, schizo-affective-dominated and schizo-dominated types of course could support the argument that a distinction between the prototypes "mood disorder" and "schizophrenia" is not always possible, but that there is an overlap of affective and schizophrenic spectra and an "antagonistic influence" between them. Clinicians need to consider the polymorphism of the bipolar disorder in order to provide adequate treatment and prophylaxis. Researchers have to consider that the boundaries of diagnostic categories are very flexible, thus making possible a psychotic continuum.

\section{References}

I. Marneros A, Akiskal H: The Overlap of Affective and Schizophrenic Spectra. Cambridge University Press; 2007.

2. Marneros A, Pillmann F: Acute and Transient Psychoses. Cambridge University Press; 2004.
3. Marneros A, Rottig S, Rottig D, Tscharntke A, Brieger P: Bipolar I disorder with mood-incongruent psychotic symptoms: a comparative longitudinal study. in press.

4. Marneros A, Rottig S, Rottig D, Tscharntke A, Brieger P: The longitudinal polymorphism of bipolar I disorders and its theoretical implications. in press. 